\title{
Integrative therapy for personality disorders: Experiences in developing integrative approaches for treatment-refractory personality-disordered clients
}

\author{
Nazir Hussain \\ Ontario Shores Centre of Mental Health Sciences, Whitby, Canada; hussain9445@yahoo.com
}

Received 17 February 2013; revised 23 March 2013; accepted 1 April 2013

Copyright (c) 2013 Nazir Hussain. This is an open access article distributed under the Creative Commons Attribution License, which permits unrestricted use, distribution, and reproduction in any medium, provided the original work is properly cited.

\begin{abstract}
Personality Disordered (herein referred to as PD) clients are challenging to statutory mental healthcare programmes. They can be difficult to diagnose: their disorders can be obscured by second-order problems such as anxiety and depression, caused by PD cognitive processes. Treatment-as-usual (the predominant model of psychiatric intervention) for PD clients in crisis tends to focus on these second-order presentations, but provide no means of identifying underlying PD. The purpose of this paper is to describe how heuristic methods of diagnosis can be used to reframe the client's distress in the context of personality disorders (according to DSM-IV criteria), and how subsequent application of integrative therapies can break their cycle of recidivism. Method: Two case studies of treatment-refractory individuals with cyclical patterns of crisis-point service engagement for selfharm or psychotic depression where heuristicl integrative therapies were used. Results: The use of integrative therapies in the case studies presented resulted in a marked change in recidivism and quality of life for each client, as measured by a significant reduction in presentation of symptoms and hypervigilance. Discussion: By understanding the maladaptive cognitive-behavioural processes of PD clients, they can be modified to reduce the client's self-defeating behavioural patterns, breaking the cycle of recidivism. However, a new diagnostic strategy must first be formulated that looks at the clients past use of mental health services to detect underlying PD.
\end{abstract}

Keywords: Personality Disorder; Mental Health
Issues; Integrative Therapy; Treatment Refractory; Borderline Personality Disorder; Suicidal Behaviour; Safety Seeking Behaviours; Emotional Dysregulation

\section{INTRODUCTION}

PDs such as Borderline Personality Disorder (BPD), represent a pervasive pattern of marked impulsivity and instability in interpersonal relationships, self-image, and affects. They are characterized through a group of behavioural patterns [1]. The PD client engages in a range of self-defeating behaviours that alienate him or her from family and long term relationships, which make operating in a social or work environment difficult, and often include substance abuse or other self-harm [2].

One way of conceptualizing what the cause of PD behaviour/patterns are biases in the clients' cognitive processes, through which they filter social experiences and self-perception [3]. Often, individuals with PD regard the world as a hostile place filled with people who hate them, and thus internalize these beliefs, viewing themselves as unlovable and unworthy [2]. PD clients regard feelings of fear, despair, and alienation as signs of personal inferiority, and attempt to control, avoid or escape from these feelings [2]. They engage the world with siege-mentality: retreating where possible, and screening interaction through defensiveness and hypervigilance [4].

PD clients have difficulty obtaining effective care in traditional therapeutic environments for two reasons. First, they tend to perceive their difficulties as stemming from the shortcomings of others. Second, their behavioural patterns often create complex roadblocks to therapy. Accounts of their experiences and feelings are often misreported or exaggerated, they have difficulty opening up and trusting, and often attack the caregivers emo- 
tionally when they feel uncomfortable [5]. Because of these roadblocks, otherwise effective care methods are often ineffective when dealing with the PD client. This leads to a cycle of engagement with mental healthcare services as follows: 1 ) they are directed to programs that are appropriate for secondary problems related to PD such as substance abuse, depression, or anxiety, and use these programs for a time with little benefit; the services do not address their primary problems nor overcome the roadblocks to effective therapy. 2) Frustrated, the client leaves the program, and returns to their normal pattern of behaviour until they reach psychological crisis and require hospitalization. 3) After the crisis has been managed they are again directed to existing programs, repeating the cycle of ineffective care, discontinuation, and crisis [6]. For most PD clients, this is a lifelong service-use pattern. Therefore, the aim of this paper is to explore how the use of heuristic methods of diagnosis and therapy can improve quality of life and reduce recidivism for treatment-refractory individuals with PD. However, one must first gain an understanding of the factors that lead to the development of PDs and the reasons why conventional therapy is not effective/roadblocks to effective care provision for PD clients. The use of such integrative therapies will be illustrated through two case studies.

\section{THE AETIOLOGY OF PERSONALITY DISORDERS}

PD is the coexistence of a range of cognitive and behavioural distortions that interact in such a manner that they cause dysfunction in a range of domains. Individually, most people exhibit one or more of these distortions; it is the profusion and severity of effect that divides a PD client from the ordinary person. These can be easily broken down into three major interrelated categories of distortion: maladaptive schema, cognitive assumptions, and safety-seeking behaviours.

Emotional schema are methods by which a person learns to cope with and use their emotional experience and interpret behaviour. PD clients tend to have very strict and limited emotional schema that lead to selfharming experience and use of emotion. They tend to see emotions as a reflection of moral quality, believe some emotions to be unacceptable, have trouble dealing with the idea of mixed emotions, and tend to see emotional reality in black and white terms [7]. They often feel distress for feeling something they see as "bad" or "negative" emotions, and as a result punish themselves. They also assume that emotions are not, or should not be subject to change [2].

Having a maladaptive emotional schema, PD clients tend to make cognitive assumptions (based on their very limited frame of emotions) onto others: they assume others have unchanging, often negative, extreme, and black-and-white emotions [2]. Rather than seeking information on another's emotion they tend to exclusively rely on the emotional landscape they project on others. This often means that a single conflict with another person will lead a PD client to project malice and hatred toward themselves onto the motivations of other people [8].

These schema, combined with a habit of projecting their cognitive assumptions on the people around them, lead PD clients to experience the world as an innately cruel and hostile place, with emotions being particularly menacing and disturbing elements. PD clients thus engage in a range of safety-seeking behaviours to protect themselves from strong emotional experiences and interpersonal interaction. This can include the use of drugs, alcohol, gambling, or compulsive sex to avoid emotional attachment [9]. It can also include self-harm (cutting, binge-eating, and burning) to punish the self for emotions, and reduce the intensity of feelings [10]. Negative self-talk and emotional self-abuse can be used to try and force the self into a rigidly defined emotional landscape [11]. Hypervigilance, aggression, violence, emotional withdrawal and antisocial behaviours are also used to drive others off before emotional interaction is necessary [12].

\section{A Disorder of Mentalization}

Mentalization is the metacognitive capacity to recognize mental states (thoughts, feelings, etc.), as different from behavior [13]. A person who lacks mentalization may not understand their own motives and have difficulty in understanding/empathizing the motives of others. PD clients do not effectively or consistently engage in the process of mentalization: they do not recognize emotional projections, ruminations, hyper vigilance, or negative self-talk to be states of mind that are subject to change, control, or intentionality. Instead they perceive these maladaptive cognitive processes as being uncontrollable and an inevitable result of their experiences. Their identity and experiences become "fused" with their emotions [14].

Similarly, PD clients lack of mentalization may result in conflation of thought with action. To many PD clients thinking about an action is identical to performing the action in a moral sense. A client who has cruel thoughts about a loved one may see themselves as cruel to that person. In essence they have a fusion of thought and action [14]. In order to provide effective care to PD clients, the focus of care must include, develop, or stimulate mentalization as a skill and then habit [15]. Teaching individuals to recognize mental processes and giving them the ability to outlast or intentionally change 
those processes allows for mastery.

\section{PD AND CONVENTIONAL THERAPY}

PD clients have a range of roadblocks to effective engagement of care in treatment-as-usual. Avoidance of emotion and a reluctance to report emotional state out of a fear of intensifying the emotion often make the client hesitant to disclose feelings to a therapist, which limiting the therapist's ability to offer effective help [5].

A PD client may also project their negative feelings onto the therapist assuming he or she thinks negatively of, or dislikes, the client and accordingly, becomes defensive [16]. Patterns of social isolation may also manifest during the therapy session: a PD client may become challenging, adversarial, or emotionally aggressive with their therapist in order to avoid personally upsetting interpersonal experiences with the therapist.

PD clients tend to distort and misrepresent events to make them more consistent with their projections [17]. It is difficult to get an accurate picture of emotionally significant events within a PD client's accounts without seeking clarification and actively looking for distortions. Furthermore, this is difficult to do without upsetting the client or falling into "paternalistic models" of care [18].

PD clients often present secondary psychiatric conditions to therapists [19]. Without making a comprehensive and heuristic assessment of the clients' psychological and cognitive state diagnostic reasoning is likely to route clients on apparent (second-order) problems such as depression or anxiety [19]. Direct treatment of presented symptoms without investigation of possible underlying personality disorders allows those disorders to remain unobserved and untreated [19].

In these cases, the focus of treatment on second-order/ symptom-focused problems at best temporarily manages crises, but until the personality disorder itself is adderssed, the anxiety and depression will return, leading to future crises.

Therefore, the roadblocks to effective care provision for PD clients require a different approach from conventional services [15]: as PD is essentially a series of cognitive and behavioural patterns that lead to a compromised quality of life, these services must be directed towards simultaneously adjusting both behaviour and cognitive patterns of the client and providing new skill development for them [2].

\section{PROVISION OF EFFECTIVE CARE FOR PD CLIENTS}

Due to the roadblocks presented by PD clients, conventional services not only fail to meet their needs, but may exacerbate their problems, reinforce the disempowering and destructive cycle of ineffective service, de- grading their quality of life. Meaningful care provision must therefore be measured by its effectiveness in circumnavigating those roadblocks [20].

An effective mental healthcare service for PD could be measured by several criteria. The first would be the reduction of a client's hypervigilance. The second would involve teaching the client to read and assess others' emotional states and opinions in a methodical manner (rather than through projection). These could allow the client to interact in social settings without reinforcing their negative perceptions about themselves and others [2]. The third would be the reduction of coping strategies used by PD clients; many of the behavioural patterns associated with $\mathrm{PD}$, such as offensive behaviour, emotional aggression, isolation, self-harm, and substance abuse are attempts to protect oneself from experiencing negative emotions or social discomfort [4]. By teaching socially effective interpersonal and self helping skills, the client may have a marked increase in quality of life. This can be achieved by educating them on how to identify the cognitive processes that result in maladaptive strategies, enabling them to engage alternate cognitive and/or behavioural processes (i.e. Mentalization) [13].

\section{Conditions for Effective Care}

Due to the tendency of PD clients to resist care and project negative emotions onto the care provider, any care environment must first and foremost feel "safe" to the client. The care provider must learn to work with resistance in order to provide effective care [15].

Offering psychoeducation to help the client develop an understanding of the basic aetiology of PD, and how it creates the cognitive/behavioural patterns that cause them distress would be the first step, and enable therapists to coach them in developing different, more effective strategies until they become habitual [21].

Emotional validation is also valuable because it helps the clients learn that their emotions are natural and acceptable. This is often an important starting point for therapy, as emotionally invalidating environments are the norm for the PD client, and have shaped their existing emotional schema [22].

As the client begins to understand how their emotional schemas affect their behaviour, the therapeutic focus turns to how the schema leads to (and is caused by) untested projections. This experience provides material and experiences the clients can work with. Their assumptions are identified and tested [21].

Mentalization of the cognitive processes allows the client to develop the skills to challenge these assumptions without prompting. They learn to verify their initial projections about other people's attitudes, and interrogate their own thought processes. Instead of reacting to ascribed emotions or attitudes, the client actively searches 
out ways to test their assumptions before acting on them [21].

Ultimately the therapeutic goal of the process is to make these skills a robust habit. They serve as a filter which helps the client become aware of the cognitive processes that make social interaction and emotional experience difficult, and actively counteract them by applying socially adaptive skills.

\section{5. (METHOD) CASE HISTORIES OF PD CLIENTS}

The following are case histories from the author's experience as a clinician applying these principles with clients who suffer from PD. In both cases the client began exhibiting pathology in their late teens, and had a history of cyclical engagement with statutory mental healthcare services for their entire adult lives. They each sustained a pattern in which they would reach a crisis point, engage services, but fail to receive appropriate care, withdraw from services and remit to crisis point again. They were considered "untreatable" by the mental health-care community at large. Data has been collected through immediate clinical interactions with the clients, combined with follow-up interviews with clients and their care-providers. Both clients provided written consent to be described in this paper. Their anonymity has been ensured through the use of pseudonyms. References to the institutions and programs were also obscured.

\section{RESULTS: CASE HISTORY 1: A.B.}

\subsection{Clinical Presentation}

Client A.B. is a 67 year-old man who has been divorced several times. He has two children out of wedlock by different mothers, but is completely alienated from them. He has held numerous low-wage, low-prestige jobs such as a janitor, meter-reader, and paperboy, but has not held any job for more than a year.

A.B. had an extremely unstable childhood. Both of his parents were alcoholics and fought in front of him as a young child. They separated while he was young, and his biological father was absent thereafter. After their separation, A.B.'s mother went through a string of short-term relationships with needy, emotionally unstable, and frequently abusive men. Several of her boyfriends physically, emotionally, or sexually abused A.B.. His mother and her partners drank in front of him; several had sex with his mother while he was watching as a young child.

A.B. had a younger brother that he compared himself to. He believed his brother received far better treatment, was better loved, smarter, healthier, stronger, and more able than him. He remains estranged from and embittered towards his brother.

In his teens he ran away from home. Jobs caused him high stress and he easily became bored with them. He had difficulty connecting with co-workers because he felt unable to trust men. At the same time he began a pattern of short-term relationships. He tended to connect with needy, emotionally unhealthy women that he met at drinking or cannabis parties. His relationships tended to be mutually abusive. He married a woman within a few weeks of meeting her and they divorced within months. With the mothers of his children he tried to maintain longer relationships, but became emotionally abusive to his children; usually through harsh criticism, which alienated both his children and their mothers.

By his mid-twenties, A.B. was using drugs and alcohol to manage his anger, resentment, and emptiness He often vented his emotions through violence, often initiating bar-fights or attacking co-workers. By twenty-seven he had begun a pattern of overdosing, suicide attempts, or suicide threats that initiated a life-long engagement with mental healthcare services. Between the ages of twenty seven and sixty six, he had not spent more than a year at a time outside of psychiatric care.

Between hospitalizations, A.B. would either live with his brother, or with a short-term girlfriend. In both cases, as the relationship became closer with his brother or girlfriend and they became emotionally engaged, he would withdraw with abusive behaviour or emotional distance. As friction increased due to his relationships/living environment/job, he would begin to self-neglect, and selfharm. He burned his arms or legs with cigarettes, refused medication or over-dosed on it. He would also stop eating, sleeping, or grooming. He would drink heavily. Eventually, he would threaten or attempt suicide, and be returned to psychiatric care. While in care he would continue to resist treatment, using suicide threats as a means of controlling the terms of care. He became highly dependent on the mental healthcare system, and progressively less able to handle life outside of it. He often responded to attempts to return him to the community with anxiety and suicide threats.

His most recent admission to mental healthcare occurred after he missed several appointments, and was found by his landlord lying semi-naked in the foetal position in his apartment. The landlord estimated that he had not eaten, nor moved from that spot for two or three days.

\subsection{Diagnosis}

Over the course of his 40-year engagement with mental healthcare services, A.B. had been variously diagnosed as suffering from psychotic depression and bipolar depression. However, traditional treatments for these disorders proved ineffective. A re-diagnosis of his condition was a major step. His behaviour, dialogue, and history were consistent with Borderline Personality Disor- 
der, and so new treatments were developed along those lines.

\subsection{Treatment History}

A.B. had been treated up to the point of his most recent admission to mental healthcare as if suffering from psychotic depression. Threats of suicide were managed with standard suicide threat management, followed by trials on varying courses of psychotropic medications. Psychotropics were only partially effective in his case; he tended to see such medication as an attempt to "control" him through his moods and behaviour.

\subsection{Treatability: A.B.}

A.B.'s resistant behaviour often made it hard to assess the efficacy of medical treatments, while the extremity of his presentation (self-harm, threats of suicide) made it difficult to focus on diagnostic measures. He appeared to healthcare services to suffer from an extreme manifestation of depressive psychosis that required immediate and focussed attention to prevent A.B. from being a danger to himself. A cognitive root to the problem was difficult to diagnose, because of the immediacy of his crisis. Likewise, the rate of recidivism in his case seemed as likely to represent severe psychoses with a medical origin as a personality disorder.

Ultimately, A.B. was considered to be a treatment-resistant case; mental healthcare workers did what they could to manage his current suicidal ideation and accepted that the solution was temporary but life-saving.

\subsection{Use of Integrative Therapy: A.B.}

A.B.'s most recent admission to psychiatric care followed his usual pattern. Once he was stabilized, he became resistive to care, and refused to take medications. As attempts were made to return him to the community, he began threatening suicide and displaying violent outbursts. Rather than treat the suicide threats as evidence of psychotic depression, and responding with suicide watch and medication, he was approached as if he were using suicide threats as a means to an end, and asked to identify what he hoped to accomplish with them. Careful use of Socratic dialogue was used to generate alternate solutions and possibilities

Therapist: I hear that you have been threatening suicide. That is pretty serious.

A.B.: I just don't know what to do.

Therapist: You must be feeling pretty upset right now. And frustrated. I can imagine that you feel like there is a serious problem, but no one really seems to understand it. When you try and tell people they totally misunderstand and react in the wrong way. You must be wondering whether or not it is even worth trying to communicate some days. Am I right?

A.B.: You know, you are the first person to say something like that to me. How did you know?

Therapist: If I were in your position I'd feel the same way. You've been having these feelings for a really long time. How could you not feel like people don't understand you?

A.B.: You're right. Most of the time I feel like there is no point to even trying.

Therapist: When you threaten suicide, I don't think you are only saying you want to kill yourself; I also think there is a problem that you are trying to address. I think you are trying to solve this problem, but you aren't sure how to address it, or how to ask for help with it. Am I right?

A.B.: Kinda'...yeah. People listen when I tell them I want to kill myself. They stop trying to tell me what to do.

Therapist: Do you think you are punishing yourself to punish other people?

A.B.: ...How did you know?! Sometimes that is exactly what I am doing... like it would serve them right if I killed myself. How do you know what is going on in my head? It's like you are the first person who understands me.

Therapist: It is understandable. You have every right to be angry with others. It is perfectly okay to be angry.

Therapist: So suicide threats solve the problem in the short term, right?

A.B.: Yeah.

Therapist: How does it work in the long term? How do people react to your suicide threats?

A.B.: Well, after a while they seem to be scared of me. They don't want to be around me.

Therapist: It sounds like threatening suicide works to solve your problem a little in the short term, then, but doesn't help in the long term. Is that fair to say?

A.B.: I don't know what else to do.

Therapist: That must be pretty frustrating too. Like you are going in circles?

A.B.: Sometimes it does.

Therapist: If you could find a better solution to your problem than threatening suicide, would you use it?

A.B.: If I could..

Therapist: Would you like to work with me to find a better solution for your problems? I think we can work together.

This opened up a dialogue that allowed A.B. to acknowledge that he had a hard time asking for help, and hoped other people would intuit what he needed. When he didn't receive the help he wanted, he used suicide threats as a means of forcing change in care. After he identified this barrier, he gradually became open to learning more effective communication skills, especially in identifying, labelling, and expressing his feelings. 
Once he was confident in expressing himself in roleplaying sessions, hypothetical communication problems, and with the staff, he was returned to his home with arranged aftercare and community care services to monitor his needs. He was encouraged to regularly practice his communication with co-residents. During follow-up sessions he showed a notable improvement of the same communication skills because of the practice.

As of the writing of this paper, A.B. has now been out in the community for over 30 months, without recidivism. He has maintained his own self-care to the best of his ability, although he remains alienated from his brother. He has met with me twice during this time period for evaluation.

\section{RESULTS: CASE HISTORY 2: C.D.}

\subsection{Clinical Presentation}

C.D. is an 82-year-old married man. His wife has children from a previous marriage with whom he has cordial, but emotionally distant relationships. Throughout his life he has worked a range of short-term unskilled labour jobs. He immigrated to Canada in 1956 and took up work as a factory worker. He was a meticulous, punctual, perfectionist and honest worker, but had difficulty developing the necessary skills to advance. He was socially isolated throughout his life, having no social circle or close friends. He was also highly religious. He met and married both of his wives through the church.

C.D. was either orphaned or abandoned at an early age, and was raised primarily in foster care and group homes. Most of his childhood was spent in a group home where he lived with nineteen other children.

In the past few years, C.D. began having thoughts that he was a child molester. He developed a delusion that he "may have" touched co-residents in the group home he was raised in, despite having no memory of having done so. These thoughts terrified him, and he rapidly developed a phobia of police and being seen in public, along with severe generalized anxiety and sporadic panic attacks. He also developed feelings of self-hatred leading to self-neglect.

His relationship with his wife became strained and made his household an extremely stressful environment. His wife would often criticize, bully and browbeat him when she suspected he was thinking "bad thoughts", telling him he had to stop thinking: that his thoughts were immoral. Eventually, C.D.'s self-neglect began severely affecting his health, and his wife had increasing difficulty providing him with the necessary care. Hospitalization became a necessary step.

C.D. developed an affect of severe anxiety: he would sit in as isolated a place as he could find, often balled into the foetal position of hugging his legs, and shivering, and either pace or rock. He was also highly irritable and easily frightened. During peak periods of anxiety he would approach staff begging them to tell him that he would be okay, that there was no sign of the police coming to get him, and that he wasn't in trouble. If he was told he was going to be okay, he would assume that they were just trying to keep him docile, and that the police were en route, which would precipitate anxious behaviour, including clinging to staff or hiding.

If his behaviours or his questioning were met with attempts to medicate him he would panic and behave aggressively, yelling and screaming that he was dying and no one was trying to help him.

\subsection{Diagnosis}

C.D.'s self-destructive patterns of behaviour were diagnosed as a manifestation of psychotic depression combined with Mixed Personality Disorder. Upon taking up his case and examining the way his thoughts perpetuated a cycle of self-destructive behaviour because he was unable to rid himself of them, combined with a tendency towards fastidiousness, and a fear of making mistakes, it seemed more likely that he suffered from an ObsessiveCompulsive Personality Disorder with co-morbidity of OCD.

\subsection{Treatment History}

The initial focus of his treatment was stabilization and equipping C.D. to care for himself. However, he proved to be highly resistant to drug therapies: virtually every available combination of drugs for depression and anxiety was tried and failed to reduce his self-destructive behaviour patterns. Other therapeutic options such as ECT were not viable due to his frailty and pacemaker.

\subsection{Treatability: C.D.}

Local mental healthcare services came to consider him treatment-resistant and non-dischargeable, due to the ineffectiveness of psychotropic medication and the persistence of self-destructive behaviours. Because of the focus on managing psychotic depression first, no talking therapies or an extensive diagnostic of his cognitivebehavioural patterns had taken place. In effect, the procedurally-correct attention on depression and its management had obscured the underlying cognitive-behaveioural causes of his depressive behaviour. The choice to treat this behaviour as a resultant of a personality disorder was made because all standard options had been exhausted without producing significant results.

\subsection{Use of Integrative Therapy: C.D.}

I approached C.D.'s case from the assumption that his behaviours were a resultant of PD than solely caused by psychotic depression, and that they were likely the cause 
of cognitive fusion meaning thought/action or emotion/ action fusion, a common feature of PDs [14].

After several sessions of interviewing I discovered that there were several major thought patterns that recurred in C.D., which led to his anxious behaviour. They were:

1) "If I think of a thing, I am likely to do or have done that thing; if I think a bad thing it is the same as having done the bad thing."

2) "If I make a mistake or do something bad, then I am a bad person."

3) "The hot, uncomfortable feelings I experience when I have bad thoughts are punishment for the thoughts."

4) "These feelings of fear and discomfort are so awful I can't bear them. I might die if I have to feel the feelings I get when I think bad thoughts."

5) "To remain a good person, and to avoid those terrible feelings that might kill me, I must fight with bad thoughts I am experiencing to make them go away.”

6) "Because I have thought terrible things about children and made mistakes, I am a bad person and the police will take me away."

This thought-pattern created a cycle by which C.D. would begin ruminating and rapidly cycle into a series of disruptive thoughts that he would fight with, which amplified the thought. He would end up in a tug-o-war within his mind leading to mounting anxiety and selfhatred.

Once I identified this pattern, I directed therapy at breaking this cycle at the cognitive root: that if the thought is a bad thing, it is equivalent to doing the bad thing. I also focussed on training him to recognize and observe thoughts as such, rather than struggling to control them.

He found it helpful to work with the metaphor of the thought as a visitor [23], it would knock at his door and come in, sometimes it would be helpful and friendly, and sometimes it would not be, but eventually it would leave. He found it very effective, once he engaged this metaphor, to ask the thought to "kindly leave" or to "go away."

Once we had diffused thought and action, we began approaching his fear of police through exposure, at first by driving near police stations, then sitting in police station parking lots. Eventually, we were able to hold an interview with officers in which they were able to tell him that to their knowledge he had done nothing bad, and there was no reason to arrest him.

After thirty-five sessions the anxious behaviour had largely ceased, and C.D. had resumed regular self-care. While he initially had described himself in solely negative terms, he now expressed very few negative selfbeliefs, and often corrected himself when he caught himself expressing these negative beliefs. During those sessions, we also educated his wife on ways to react if he started expressing anxious behaviour that would help him disengage from the thought-pattern rather than struggling with it. He was able to return to his marital home under the care of his wife, supported by community care programs. I have followed up several times. There has been no recurrence of self-neglect and he has been able to function on a day-to-day basis with manageable anxiety.

\section{RECOMMENDATIONS AND CONCLUSIONS}

PD clients such as these have suffered from a major reduction in quality of life over a protracted period because they have received care that addressed seconddary manifestations (anxiety, depression) without addressing a significant root problem. Existing healthcare service practices made it difficult to approach these clients heuristically, which led to inappropriate service to the clients.

The services these clients received followed the standard model of care, managing crisis then addressing the diagnosed depression or anxiety with psychopharmacology. This procedure could not effectively account for recidivism as it did not allow the services to identify the clients' underlying problems. Both clients had been considered "treatment-resistant", and often left therapists and care staff.

By approaching them from a more heuristic method, their underlying disorders became more apparent, and their specific cognitive patterns could be explored. Once these were understood, it was possible to integrate skillbuilding and cognitive-behavioral approaches with existing therapeutic and psychopharmacological intervenetion. The result was a marked change in recidivism and quality of life for each client: they experienced a significant reduction in presentation of symptoms, hypervigilance, and a notable improvement in quality of relationships.

These improvements in quality of life, or the application of the methods that enabled them, would not have been possible if the standard methods of care-provision alone had been followed. Moreover, existing diagnostic methodologies for evaluating PD are unreliable as they require acquisition of yes/no answers during diagnostic interviews based on a symptom list that does not obtain information on such things as frequency or severity of behaviors and cognitions, nor observable objective criteria. This suggests a scope for either a change in diagnostic methodology or for a more integrative approach for all high-recidivism clients in order to ensure underlying PD may be addressed. Thus, this paper argues for a comprehensive exploration of PD symptoms and the application of integrative CBT therapies. 


\section{LIMITATIONS}

This paper is based on the results demonstrated from two clinical cases, and thus lacks a control group to compare the results. Additionally, it is important to acknowledge that the cases mentioned should be seen as tools to demonstrate how integrative therapy can be effectively used in treating PD clients. A large sample size and control group is recommended for future research and generalizeability of this subject.

\section{ACKNOWLEDGEMENTS}

My sincere thanks go to Barbara Mildon for her compassion, encouragement and support in the publication of this work. I would also like to thank Sanaz Riahi for her ongoing sincere support with research initiatives. I am deeply grateful for Sophie Wong for her refreshing critique and Socratic dialogues during the completion of this paper. In addition, credit goes to my loving family who provided me with unconditional love and support throughout this project. Last but not least, this work would not have been possible without the help of individuals with PD and their loved ones who allowed me into their lives and enriched my perspective on thoroughly understanding their struggles.

\section{REFERENCES}

[1] Gunderson, J. and Links, P. (2005) Borderline personality disorder: A clinical guide. 2nd Edition, American Psychiatric Press, Washington DC.

[2] Sieswerda, S., Arntz, A. and Kindt, M. (2007) Successful psychotherapy reduces hyper vigilance in borderline personality disorder. Behavioural and Cognitive Psychotherapy, 35, 387-402. doi:10.1017/S1352465807003694

[3] Dimaggio, G., Carcione, A., Salvatore, G., Semerari, A., and Nicolò, G. (2010) A rational model for maximizing the effects of therapeutic relationship regulation in personality disorders with poor metacognition and overregulation of affects. Psychology and Psychotherapy: Theory Research and Practice, 83, 363-384. doi:10.1348/147608310X485256

[4] National Institute Collaborating Centre for Mental Health (2009) Borderline personality disorder: Treatment and management. National Institute for Health and Clinical Excellence, Holborn.

[5] Foerstch, C., Manning, S.Y. and Dimeff. L. (2003) Difficult-to-treat patients: The approach from dialectical behaviour therapy. In: Leahy, L.R., Ed., Roadblocks in Cognitive Behavioural Therapy, The Guildford Press, New York, 225-273.

[6] Goin, K.M. (2001) Borderline personality disorder: The importance of establishing a treatment framework. Psychiatric Services, 52, 167-168. doi:10.1176/appi.ps.52.2.167

[7] Leahy, L.R. (2003) Emotional schemas and resistance. In:
Leahy, L.R., Ed., Roadblocks in Cognitive Behavioural Therapy, The Guildford Press, New York, 91-115.

[8] Leahy, L.R. (2003) Roadblocks in cognitive-behavioural therapy. The Guildford Press, New York.

[9] Sarkar, J. (2012) Clinical topics in personality disorder. Royal College of Psychiatry, London.

[10] Linehan, M.M. (1993) Dialectical behavior therapy for borderline personality disorder. The Guildford Press, New York.

[11] Paris, J. (1996) Social factors in the personality disorders: A biopsychosocial approach to etiology and treatment. Cambridge University Press, New York. doi:10.1017/CBO9780511722165

[12] Paris, J. (2008) Treatment of borderline personality disorder: A guide to evidence-based practice. The Guildford Press, New York.

[13] Bateman, A. and Fongay, P. (2008) Mentalization-based treatment for BPD. Social Work in Mental Health, 6 187-201. doi:10.1300/J200v06n01_15

[14] Hayes, S. (2012) Acceptance and commitment therapy (theories of psychotherapy). The American Psychological Association, Washington DC.

[15] Jones, B. and Miller, S. (2011) Emerging as a personality disorder service. Psychoanalytic Psychotherapy, 25, 191208. doi:10.1080/02668734.2011.576499

[16] Bourke, E.M. and Greyner, F.S.B. (2010) Psychotherapists' response to borderline personality disorder: A core conflictual relationship theme analysis. Psychotherapy Research, 20, 680-691. doi:10.1080/10503307.2010.504242

[17] Holland, J.S. (2003) Avoidance of emotion as an obstacle to progress. In: Leahy, L.R., Ed., Roadblocks in Cognitive Behavioural Therapy, The Guildford Press, New York, 116-131.

[18] Allen, M.D. and Whitson, S. (2004) Avoiding patient distortions in psychotherapy with borderline personality disorder patients. Journal of Contemporary Psychotherapy, 44, 211-227.

[19] Gunderson, J. (2010) Update on borderline personality disorder. Gatineau, Quebec.

[20] Zanarini, M.C. (2009) Psychotherapy of borderline personality disorder. Acta Psychiatrica Scandinavica, 120, 373-377. doi:10.1111/j.1600-0447.2009.01448.x

[21] Bateman, A., Ryle, A., Fongay, P. and Kerr, B.I. (2007) Psychotherapy for borderline personality disorder: Mentalization based therapy and cognitive analytic therapy compared. International Review of Psychiatry, 19, 51-62. doi:10.1080/09540260601109422

[22] Chapman, A. and Gratz, K. (2011) The dialectical behavior therapy skills workbook for anxiety: Breaking free from worry, panic, PTSD \& other anxiety symptoms. New Harbinger Publications, Oakland.

[23] Hanh, H.T. (2006) Anger: Wisdom for cooling the flames. Riverhead Books, New York. 